\title{
BINARY OPTIONS AS A MODERN FENOMENON OF FINANCIAL BUSINESS
}

\author{
Andrea KOLKOVÁ, Lucie LENERTOVÁ
}

\begin{abstract}
Binary options are a new instrument of the financial market. The aim of this paper is to analyze the use of binary options with trading and to illustrate this on the practical example of trades based on Bollinger bands indicator. Currency pair EUR/USD and 6912 time series values of this instrument will be put to analysis. The contribution will be evaluated 8 strategies based on Bollinger Bands. There will be used a backtesting method. From the results follows the most trades could have been realized with the use of Bollinger bands with a double deviation. This strategy, however, also showed the greatest percentage of failed trades. On the contrary the fewest transactions could have been carried out with Bollinger bands with a triple deviation and the MACD filter.
\end{abstract}

\section{KEY WORDS}

Binary option, Bollinger bands, backtest, forex

JEL

G $10 C O D E$

\section{INTRODUCTION}

Binary Option is a relatively new tool of the financial markets. Their history dates back to 2008 . They are considered very risk investments. Trading binary options, of course, requires a thorough analysis of the appropriate market. By means of technical analysis the development of underlying asset can be predicted to some extent and thus binary options can be put into very attractive investments in terms of revenue. In this paper we used a technical analysis as a tool for prediction of exchange rate change.

The aim of this paper is to analyze the use of trading binary options and to illustrate this on the practical example of trades based on the Bollinger bands indicator. Eight strategies where Bollinger bands are the basis will be subjected to the analysis.

\footnotetext{
${ }^{6}$ Correspondence address: Andrea, Kolková, Ing. PhD.; 595228143; email address: andrea.kolkova@vspp.cz, Vysoká škola podnikání a práva, a.s., Lucie Lenertová, Ing., email address: lucie.lenertova@,vspp.cz, Vysoká škola podnikání a práva, a.s.
} 
To realize the objective a method of back-testing will be used for a period of one month in a fiveminute time frame. This means that 6912 exchange rate values were subjected to the analysis. The currency pair EUR/USD has been used as an underlying asset for its high liquidity.

\section{THEORETICAL REFERENCE}

As stated by Rick Thachuk (2010) „,binary options have, for some time, been available over the counter but they are typically marketed as exotic options to institutions and often packaged with other derivative-type products".

History of binary options is relatively young. As reported by Jurník (2013) it dates back to 2008, when the financial instrument was introduced to the public as a marketable asset at the Chicago Board Options Exchange (CBOE). American Stock Exchange and Chicago Board Options Exchange (CBOE) listed binary options on select stocks and indices. However, these have not attracted any significant retail customer base.

However, according to Jaworsky (2006), the first binary options were presented by CBOE at a press conference on 10 July 2006 as one of its main financial innovation. Due to its simplicity, binary options have become very popular among traders and today are widely traded around the world. The huge interest in trading binary options also meant the emergence of many new brokers, who started to specialize in this very business instrument. Today, there exist approximately four hundred of them.

During the last few years, though, a web-based electronic retail market has developed that is becoming popular, especially among investors with little prior investment experience or who have limited capital.

According to Cofnas (2013), ,this nascent market is reminiscent of where the retail forex market was eight or 10 years ago. It is a new investment alternative with low cost entry where all trading is conducted over a web-based, real time platform on which customers can trade with a simple click of the mouse". Until recently they were hard to obtain, but a new generation of web-based electronic trading platforms, as well as several market innovations designed to simplify the trading decision, are generating excitement and activity in retail binary options trading.

Although the first trades were realized on the CBOE (Jaworski, 2006), today the vast majority is carried out on the Over the Counter markets (OTC). OTC is a method of trading when market participants trade directly together. In practice, the counterparty of the majority of the trades is one of the brokers.

As stated by Miyake, at all. (2013) „Binary options are popular in OTC markets for hedging and speculation. They are also important to financial engineers as building blocks for constructing more complex option products. Thus, binary options are simple but give important implication in considering various option pricing problems,,.

Binary options are not only interesting investment instrument, but also an important tool for designing complex financial derivatives such as equity-linked securities (ELS). They can even form the basis of several exotic options such as asset-or-nothing options, supershare options, gap options etc., as stated Kim Hong-Joong, at all. (2011).

\subsection{Types of Binary Options}


A binary option, also called a digital or fixed return option, has only two possible outcomes at expiry, each of which pays out a fixed value, depending on whether or not a certain condition has been fulfilled (Jurník 2013). There are several types of binary options.

The basic type is called the High / Low binary option. If a high option is used, then a predetermined profits encashed in case that at expiry the price of the underlying asset will rise by one or more ticks (respectively pips for currency pairs). With the Low option it's quite the reverse. An integrated, predetermined profit is encashed in case of fall in the underlying asset. This type of option is the most common and it may be obtained at each broker running a business with binary options (Thacuk, 2016).

Another type is Above / Below binary option. In this case, we estimate that the price at expiry is above or below a certain price level. This price level is usually different than the current price, which in the previous case is known as the strike price.

A third possible option is a type Touch / No Touch binary option. This option is profitable if it reaches (with touch option), or does not reach (with no touch options) predetermined boundaries in the time before expiry.

In the case of transactions with the type of Boundary binary options, the profit is realized in the case that at the moment of expiry the price of the underlying asset will be situated within predetermined boundaries.

The only kind of binary options, with which time doesn't matter on closing the deal but the price, is called KIKO (Knock-In and Knock-Out). A broker outlines two price levels, one above and one below the strike price. The task of the trader is to correctly predict which of these price levels will be hit sooner, while it does not matter when it happens.

The most complicated kind of binary options is known as the Ladder. Several price levels which form an imaginary ladder on each side of the current price are stated by the broker. A trader can speculate, below or above which level the rate at the expiry will be. Issued profitability for each level is not fixed until opening trade but varies depending upon where the current rate is. This type of option, however, is not common, and most brokers do not offer it.

Further options can be divided according to the expiry date. This can vary from minutes to days. Usually the longest time binary option is offered with monthly expiration. However more popular are according to Thachuk (2010) shorter options with an expiry of 5,15 minutes, an hour or a day. In this paper, a 15 minute binary option is used.

\subsection{Option Valuation}

Let us assume that the underlying assets follow geometric Brownian motions. Based on no arbitrage arguments and no cost for trading. Then the awards binary option can use Black and Sholes derived equation for the valuation of European stock options.

Today quite a lot of researchers deal with the option valuation including binary option and thus new methods for valuating options arise. For example Hong joong and Kyoung-sook Moonz (2011) constructed a new adaptive time-stepping hybrid difference method (Type I) and a method with the combination of two uniform meshes (Type II). They are proposed to solve the Black-Scholes partial differential equation with a pay containing discontinuities. 
Further, for example, Zmeskal (2010), Miyake (2016) or Thavaneswarana at all. (2013) define valuating options on the basis of fuzzy logic."

\subsection{Technical Analysis of Binary Options}

Technical analysis is based on the study of supply and demand. A technical analyst's task is to recognize a situation at market, which had repeatedly resulted in a certain development of exchange rate (da Costa at all, 2015). A strategy for future timing of the purchase or sale is then constructed at this historical development.

Technical analysis works with various types of graphs, the most widely used is the candlestick chart. We distinguish between two groups of methods of technical analysis, graphical and based on technical indicators. In this paper, the indicator Bollinger bands is used in connection with filters Stochastic Oscillator, Relative Strength Index (hereinafter referred to as RSI) and Moving Average Convergence Divergence (MACD hereinafter).

\section{RESEARCH METHOD}

The aim of this paper is to analyze the use of trading binary options and to illustrate this on the practical example of trades based on the Bollinger bands indicator.

8 strategies will be put to analysis, where as the basis is the indicator Bollinger Bands. Those strategies are Bollinger Bands with the twice standard deviation and the treble standard deviation. There will be used a backtesting method. Currency pair EUR/USD will be put to analysis. The currency pair EUR/USD has been used as an underlying asset for its high liquidity. The length of the time period is one month (January). Price will be tested on five minutes time-frame. It means 6912 foreign currency values will be put the analysis. Candlestick charts in this paper are drawn from the program Metatrader 4.

After evaluating the prices using technical analysis, they were selected signals to buy or sell. Be trated hight/low binary option with 15 minutes expiration.

Bollinger bands consist of three curves, as shown, for example, by Elder (2006). Medium (hereinafter mean) is an expression of the moving average of closing prices of length $\mathrm{n}$ of trading days (usually 20 day moving average). This is usually referred to as Simple Moving Average (SMA). The upper zone is equal to SMA plus $r$ times the standard deviation and the lower band minus the same multiple of standard deviation. The mean describes the relationship,

$$
S M A=\sum P_{k} / k, \text { where }
$$

$P$ represents the closing price of the asset and $k$ represent the perion considered. Standard deviation can be describe,

$$
\sigma=\sqrt{\frac{1}{n} \cdot\left(P_{k}-S M A\right)} .
$$

Strategy based on Bollinger bands is based, according to Bollinger (1992), on the simple logic that if $95 \%$ of the value is inside the zone, then the intersection zone could represent a signal to change the trend so that the further developments in the exchange rate would go again between the upper and lower zone. Strategies used for the application in this article is based on the research published 
by Kolková (2016). Signal for a change of the trend in this strategy is the intersection of the upper or lower zone of Bollinger bands.

Individual indicators alone, however, often provide a lot of false signals. It is therefore appropriate to combine individual indicators. Several works about relatively high uncertainty of strategies based on only one indicator have been Publisher, for examle the web BabyPips.com (2016) published the results of a five-year backtest on selected indicators. This test revealed that only MACD indicator and Ichimoku Kinko Hyo is possible to use long-term separately. Therefore, they will be added filters then, Relative strenght index (RSI), Moving Average Convergence Divergence (MACD) and Stochastic Oscilator (SO).

$\mathrm{SO}$ is a oscilator indicator that indicates when it is probable that the current trend turns. Theory of this indicator says according to Cory Janssen at all. (2016), if the indicator is growing, exchange rates have a tendency to conclude candle on the bull and vice versa. Net stochastik $(\% \mathrm{~K})$ can be expressed as,

$\% K=\frac{C-L}{H-L} \cdot 100$, where

$C$ is today price, $L$ is the lowest price for a selected number of days, $H$ is the hights price for a selected number of days. And the slow stochastic describes relationship,

$\% D=\frac{3-\operatorname{sum}(C-L)}{3-\operatorname{sum}(H-L)}$

If this signal given by Stochastic oscillator is also supported by crossing the Bollinger Bands on the appropriate candle, it can be regarded as a signal to the whole strategy.

Relative Strength Index (RSI) belongs again to a group of oscilator indicators. The author is an analyst Welles J. Wilder. RSI is defined by Reinkensmeyera (2014) as an indicator, which compares the size of the growth and decline rates in an attempt to determine overbought and oversold market. RSI describes relationship,

$R S I=100-\frac{100}{1+R S}$, where

$R S$ is growth in net average closing prices for a selected number of days divided downward in net average closing prices for a selected number of days.

For the strategy using RSI there is applied again relatively simple logic. The signal is when the RSI curve crosses the limit of $30 \%$ from below or the limit of $70 \%$ from above.

Moving Average Convergence Divergence (MACD) is a trend indicator that shows the relationship between two moving averages of exchange rates. The MACD is calculated by subtracting the 26day exponential moving average (EMA) from the 12-day EMA.

$M A C D=E M A_{\left(k_{12}\right) n}-E M A_{\left(k_{24}\right) n}$, where

$k$ represents the number of periods included in the calculation of the EMA, and $n$ represents the relative position of the current period. 
To determine the signal is then a nine-day EMA called Signal Line by Cory Janssen at all. (2016) or Elder (2006) put into the chart.

\section{RESULTS}

During the period under review it was possible to carry out 473 trades based on strategy Bollinger bands with twice the standard deviation. Out of these trades there were with a 15 minute binary option 206 trades profitable and 267 lossy. The use of only Bollinger bands with a double deviation is unprofitable and can be likened to a random choice of trades.

By multiple increasing of the standard deviation to treble we will reach $99.7 \%$ probability that the values of the exchange rate move in the range of both bands. It is therefore clear that the signals will be more reliable, but at the expense of their number. For a specified period it was possible to implement with 3 deviations only 17 trades. Out of these signals 12 trades would end with a profit. That is $70 \%$ of the correct signals.

Strategy with filter SO was evaluated again in a month period. When using a double deviation of Bollinger bands there occurred 63 clear signals during this period. These signals resulted in 41 profitable and 22 unprofitable trades. The Strategy provides a $65 \%$ profitable trades and can therefore be considered successful.

When using a triple deviation and a filter of stochastic oscillator there could be made only four trades for the whole period. Three of them were profitable. There were thus $75 \%$ profitable trades.

RSI filter with a double deviation of Bollinger bands provided only 40 clear signals for the period. Out of these signals 22 trades were successful. It means that under this combination of indicators there are $55 \%$ profitable trades.

Over a period of one month indicator Bolinger bands with three deviations and RSI filter has given a total of five signals. Out of these five, four signals were profitable. It can be stated that there were $80 \%$ profitable trades.

As a signal is then used the situation of the MACD and a signal line intersection or the MACD and zero line intersection, or according to Kaufman (2013) the divergence of price and the MACD indicator may be used. In this paper a fundamental intersection with the signal lines is concidered a signal.

During this period it was possible in combination with a double deviation of Bollinger bands carry out 35 trades. Out of these signals 21 were profitable and 14 unprofitable, which represents $60 \%$ success rate. In the case we would eliminate the candles that intersect mean, then the success rate would be $67 \%$.

The Bollinger bands indicator with three deviations and the MACD filter gave only one signal for the whole period. This signal was profitable. The combination of the filter and the indicator provided in this timeframe $100 \%$ profitable trades.

\section{DISCUSSION AND CONCLUSION}


The following table summarizes the results of the backtest. The first column includes a test strategy, the following one the number of transactions. The last column defines how many of these trades would be profitable in the case of 15- minute binary option application.

\section{Table 1 Summary of the backtest results}

\begin{tabular}{|c|c|c|c||}
\hline & Number of Trades & $\begin{array}{c}\text { Number of } \\
\text { Profitable Trades }\end{array}$ & $\begin{array}{c}\text { Percentage } \\
\text { of Profitable } \\
\text { Trades }\end{array}$ \\
\hline $\begin{array}{c}\text { Bollinger bands with a double } \\
\text { deviation }\end{array}$ & 473 & 206 & $44 \%$ \\
\hline $\begin{array}{c}\text { Bollinger bands with a triple } \\
\text { deviation }\end{array}$ & 17 & 12 & $70 \%$ \\
\hline $\begin{array}{c}\text { Bollinger bands with a double } \\
\text { deviation Filter: Stochastic } \\
\text { oscillator }\end{array}$ & 63 & 41 & $65 \%$ \\
\hline $\begin{array}{c}\text { Bollinger bands with a double } \\
\text { deviation } \\
\text { Filter: RSI }\end{array}$ & 40 & 22 & $55 \%$ \\
\hline $\begin{array}{c}\text { Bollinger bands with a double } \\
\text { deviation Filter: MACD }\end{array}$ & 35 & 3 & $75 \%$ \\
\hline $\begin{array}{c}\text { Bollinger bands with a triple } \\
\text { deviation Filter: Stochastic } \\
\text { oscillator }\end{array}$ & 4 & 4 & $80 \%$ \\
\hline $\begin{array}{c}\text { Bollinger bands with a triple } \\
\text { deviation } \\
\text { Filter: RSI }\end{array}$ & 5 & 1 & $100 \%$ \\
\hline $\begin{array}{c}\text { Bollinger bands with a triple } \\
\text { deviation Filter: MACD }\end{array}$ & 1 & & \\
\hline \hline
\end{tabular}

(Source: Author, 2016)

The table shows that most trades could have been realized with the use of Bollinger bands with a double deviation. This strategy, however, also showed the greatest percentage of failed trades. On the contrary the fewest transactions could have been carried out with Bollinger bands with a triple deviation and the MACD filter.

From the results of the percentage success rate of individual trade transactions can be marked Bollinger bands strategy with triple tolerance as the most successful and the use of the MACD as a filter of unsuitable signals. This strategy showed no false signal during the reporting period. However, it should be noted that throughout the period it gave only one trade opportunity. It is a question of money management, whether a strategy providing multiple signals would not be more profitable with the limited resources at one trade. This may be a subject of further research.

\section{REFERENCES}

[1] Babypis.com (2015) What is the Best Technical Indicator in Forex? http://www.babypips.com/school/elementary/common-chart-indicators/what-is-the-mostprofitable-indicator.html\#ixzz42VT4RrgO. Consulted: 8. 42013 
[2] Blain Reinkensmeyer. (2014) Technical Analysis, Using the Relative Strength Index. https://www.stocktrader.com/2007/05/29/technical-analysis-using-the-relative-strength-index/ Consulted: 1.4.2016.

[3] Bollinger, John. (1992) Using bollinger bands. Stocks \& Commodities. 10.2: 47-51.

[4] Confas A. (2013) Pros and cons of binary options. Futures: News, Analysis and Strategies for Futures, Options and Derivatives Traders. March 2013. Vol. 42 Issue 2, p 10-10.

[5] da Costa, T. R. C. C., Nazário, R. T., Bergo, G. S. Z., Sobreiro, V. A., \& Kimura, H. (2015). Trading system based on the use of technical analysis: A computational experiment. Journal of Behavioral and Experimental Finance, 6, 42-55.

[6] Cory Janssen, Chad Langager and Casey Murphy. (2016) Technical Analysis, Indicators And Oscillators. http://www.investopedia.com/university/technical/techanalysis10.asp Consulted: 31.3.2016

[7] Elder, A. (2006) Tradingem k bohatství. Tetčice: Impossible, s.r.o.. ISBN 80-239-7048-8.

[8] Jaworski, A. (2006) CBOT Launches Binary Options. Securities Industry News. 18, 27, 11, 24.7., 2006. ISSN: 10896333.

[9] Jurník, D. (2013) Co jsou to binární opce a jak to funguje. http://www.binarniopce.com/manual-binarnich-opci/co-jsou-to-binarni-opce-a-jak-to-funguje Consulted: 8.4 2013

[10] Kaufman, P.J. (2013) Trading Systems and Methods, fitht edition. New York: John Wiley and Sons. ISBN 1118236033.

[11] Kim, Hong-Joong; Moon, Kyoung-Sook. (2011) Variable time-stepping hybrid finite difference methods for pricing binary options. Bulletin of the Korean Mathematical Society. Volume 48, Issue 2, 2011, pp.413-426, Publisher : The Korean Mathematical Society

[12] Kolková, A. (2016) Bollinger Bands use technical analysis in the forex business. Aktuálne problémy podnikovej sféry 2016. In press.

[13] Miyake, M, Inoue, H, Shi, J, \& Shimokawa, T 2014, 'A Binary Option Pricing Based on Fuzziness', International Journal Of Information Technology \& Decision Making, 13, 6, pp. 1211-1227, Business Source Premier, viewed 26. 4. 2016.

[14] Rick Thachuk (2010) Binary options - the next big retail investing boom?. FOW [online]. 2010. ISSN 14629658.

[15] Thavaneswarana, A. Appadoob, S.S. Frank, J (2013) Binary option pricing using fuzzy numbers. Applied Mathematics Letters, Volume 26, Issue 1, January 2013, Pages 65-72

[16] Zmeskal, Z. Generalized soft binomial American real option model (fuzzy-stochastic approach). European Journal of Operational Research, 207 (2010), pp. 1096-1103 